\title{
Performance of a Compression-absorption Heat pump System Driven by Low-temperature Geothermal Water
}

\author{
Qiu Zezheng \\ ${ }^{1}$ School of Aviation Science and Engineering \\ Beijing University of Aeronautics and Astronautics \\ Beijing, China \\ ${ }^{2}$ Wuhan 2nd ship design and research institute \\ Wuhan, China \\ qiuzz2011@126.com \\ Leng Wenjun \\ Wuhan 2nd ship design and research institute \\ Wuhan, China \\ 1sxwuhan1993@hotmail.com
}

\author{
Wang Jun \\ School of Aviation Science and Engineering \\ Beijing University of Aeronautics and Astronautics \\ Beijing, China \\ wangjun@buaa.edu.cn \\ Pang Liping \\ School of Aviation Science and Engineering \\ Beijing University of Aeronautics and Astronautics \\ Beijing, China \\ pangliping@buaa.edu.cn
}

\begin{abstract}
This paper analyzes the performance of a compression-absorption heat pump (CAHP) system driven by low-temperature geothermal water. Two models, respectively, for the generator and whole system using ammonia-water as the working fluid are proposed. The results show that there is an optimum concentration around $65 \%$ for the system. The maximum of overall heat transfer coefficient can be obtained with optimum spray density between 0.13 and $0.19 \mathrm{~kg}^{-1} \cdot \mathrm{m}^{-1}$ of ammonia water solution. Operating with a high heat sink temperature between 70 and $85^{\circ} \mathrm{C}$, and a low heat source temperature from 25 to $40^{\circ} \mathrm{C}$, the COP of the system is above 4.
\end{abstract}

Keywords- CAHP; COP; vertical out-tube falling film; generator; ammonia-water

\section{NOMENCLATURE}

COP the electrical coefficient of performance

$h$ enthalpy $\mathrm{J} / \mathrm{kg}$

$\delta$ film thickness $\mathrm{mm}$

$v$ velocity of $\mathrm{y}$ direction $\mathrm{m} / \mathrm{s}$

$u$ velocity of $\mathrm{x}$ direction $\mathrm{m} / \mathrm{s}$

$\xi$ solution concentration

$\lambda$ coefficient of heat conductivity

$\Delta \mathrm{H}$ enthalpy difference $\mathrm{J} / \mathrm{kg}$

$\rho$ density $\mathrm{kg} / \mathrm{m} 3$

$m$ mass $\mathrm{kg}$

n\& mass transfer of ammonia vapor $\mathrm{kg}$

$\varepsilon$ compression ratio

$U_{g}$ heat transfer coefficient of generator $\mathrm{w} /(\mathrm{m} 2 \cdot \mathrm{k})$

$V$ volume flow $\mathrm{m} / \mathrm{s}$

$\eta_{\text {is }}$ isentropic efficiency

$f$ cycle ratio

$D_{m}$ mass transfer coefficient $\mathrm{mm}$

$D_{o}$ outside diameter $\mathrm{mm}$

$D_{i}$ inner diameter $\mathrm{mm}$

Subscripts

$1 \sim 12$ condition points of Fig .1

0 initial state

$a$ absorber

$g$ generator $w$ water

\section{INTRODUCTION}

In china the low-temperature geothermal water below $50^{\circ} \mathrm{C}$ is plentiful, and there is also a lot of geothermal tail water and waste heat water, which are discharged with the similar temperature. In addition, the energy consumption for heating is tremendous. It is meaningful for us to recover the low-temperature geothermal water and waste heat efficiently to supply heating. Heat pump is an efficient technology to reduce energy consumption, which can be used to recover low-temperature heat and meet the heating demand.

Among heat pump technologies, the potential of the CAHP cycle has been recognized for a long time ${ }^{[1]}$. Comparing with the traditional compression heat pump, CAHP can get a high heat sink temperature with a lower compression ratio ${ }^{[2][3]}$, and the system can be operated efficiently with low-temperature water ${ }^{[4]}$. In addition, the generator and absorber temperature glide can be fitted to the heat source and heat sink temperatures varying, leading to a higher $\mathrm{COP}^{[5]}$.

The component in the CAHP system has a substantial influence on COP ${ }^{[6]}$. Several earlier studies showed the heat transfer coefficient of the generator in the test plant influences COP and other state variables, and COP increases sharply with improving heat transfer of generator ${ }^{[7]}{ }^{88}$. Hence, a proper design of generator is essential ${ }^{[9]}$. The advantages of vertical falling-film heat transfer are widely recognized ${ }^{[10]}$, but as for the low-temperature heat source is very limited.

With respect to working fluids, the ammonia-water mixture is the most interesting one because of its excellent properties and large experience handling in industrial applications ${ }^{[11]}$. Thus ammonia is chosen for the present study. Therefore, the objective of this study is to analyze the performance of CAHP system driven by lowtemperature geothermal water. Two models, respectively, for the generator and whole system using ammonia-water as the working fluid are proposed, and the effects of 
different concentration of strong solution, cycle ratios, heat source temperature and spray density on the generator are performed.

\section{SYSTEM DESCRIPTION}

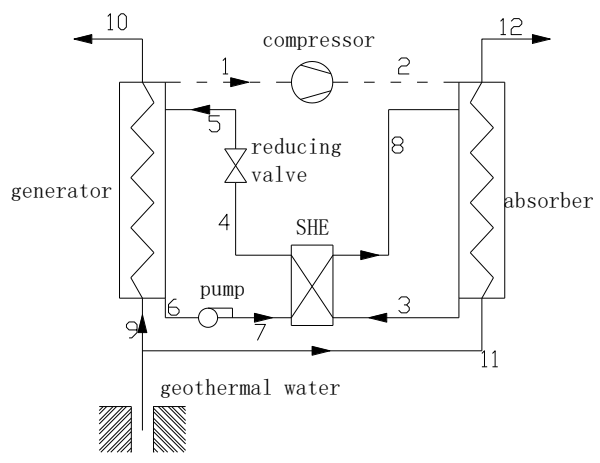

Figure 1. Schematic diagram of CAHP system

As shows in Fig .1, The CAHP cycle includes a compression stage and an absorption stage. The compressor raises the gas which desorbed from the generator to a high pressure and then the gas enters into the absorber where contact with the weak solution. In the absorber, the gas is absorbed by the weak solution, and the absorption heat is released to the heat sink. After that the rich solution preheats the weak solution in the SHE and passes through the expansion valve and enters the generator again.

\section{METHODOLOGY}

\section{A. Generator simulation}

The schematic of the generator is represented in Fig .2. The generator is a single-pass counter current vertical outtube falling film heat exchanger with the solution outside the smooth tubes and the geothermal water inside the tubes.

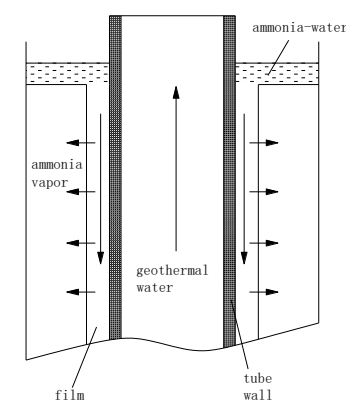

Figure 2. A vertical out-tube falling film generator

\section{B. Generator boundary conditions}

The governing equations are given as follows:

Continuity equation

$$
\frac{\partial(\rho U)}{\partial x}+\frac{\partial(\rho V)}{\partial y}=0
$$

Momentum equation

$$
\rho U \frac{\partial U}{\partial x}+\rho V \frac{\partial U}{\partial y}=\frac{\partial}{\partial y}\left(\mu \frac{\partial U}{\partial y}\right)+\rho g
$$

Energy equation

$$
\rho C_{P} U \frac{\partial T}{\partial x}+\rho C_{p} V \frac{\partial T}{\partial y}=\frac{\partial}{\partial y}\left(\lambda \frac{\partial T}{\partial y}\right)
$$

Mass conservation equation

$$
\rho \mathrm{U} \frac{\partial \xi}{\partial x}+\rho V \frac{\partial \xi}{\partial y}=\frac{\partial}{\partial y}\left(\rho D_{m} \frac{\partial \xi}{\partial y}\right)
$$

TABLE I. INPUTS OF THE GENERATOR MODEL

\begin{tabular}{|l|l|c|c|}
\hline Variable & \multicolumn{1}{|c|}{ Value } & Variable & Value \\
\hline$\delta$ & $2 \mathrm{~mm}$ & $V_{w}$ & $100-500 \mathrm{~L} / \mathrm{h}$ \\
\hline height & $5 \mathrm{~m}$ & $P$ & $0.2-2 \mathrm{MPa}$ \\
\hline$D_{i}$ & $21 \mathrm{~mm}$ & $V$ & 0 \\
\hline$D_{o}$ & $25 \mathrm{~mm}$ & $\Gamma$ & $0.06-0.26 \mathrm{~kg} \cdot \mathrm{m}^{-1} \cdot \mathrm{s}^{-1}$ \\
\hline$\xi$ & $55 \%-70 \%$ & $T_{9}$ & $30-40^{\circ} \mathrm{C}$ \\
\hline
\end{tabular}

The boundary conditions are given as follows:

$1)$. Entrance boundary conditions

$$
\begin{gathered}
\left.\delta\right|_{x=0}=\delta_{0} \\
\left.V\right|_{x=0}=0 \\
\left.T\right|_{x=0}=T_{0} \\
\left.\xi\right|_{x=0}=\xi_{0} \\
\left.\mathrm{U}\right|_{\mathrm{X}=0}=\frac{\Gamma}{\rho \delta_{0}} \mid \mathrm{x}=0
\end{gathered}
$$

2). No slip boundary condition

$$
\left.U\right|_{y=0}=\left.V\right|_{y=0}
$$

3). Non-filtration boundary conditions

$$
\begin{gathered}
\left.\frac{\partial \xi}{\partial y}\right|_{y=0}=0 \\
\left.T\right|_{y=0}=T_{0}
\end{gathered}
$$

4). Boundary conditions of liquid-vapor interface

$$
\begin{gathered}
\left.\lambda \frac{\partial \mathrm{T}}{\partial \mathrm{y}}\right|_{y=\delta}=-\Delta H \frac{\rho D_{m}}{\xi} \frac{\partial \xi}{\partial y} \\
\left.\frac{\partial U}{\partial y}\right|_{y=o}=0 \\
\left.F\left(P_{g}, T_{f}, C_{f}\right)\right|_{y=\delta}=0 \\
\left.n \&\right|_{y=\delta}=\left.\left(-\rho V+\rho U \frac{d \delta}{d x}\right)\right|_{y=\delta}=-\left.\frac{\rho D_{m}}{\xi} \frac{\partial \xi}{\partial y}\right|_{y=\delta}
\end{gathered}
$$

The flow rate, solution concentration and temperature can be calculated by the above mathematical model.

\section{Cycle simulation}

Geothermal water below $40{ }^{\circ} \mathrm{C}$ is used to drive the CAHP system and also to boost the temperature. In this study the inlet and outlet condition of the two components is considered, and the absorber and SHE (solution heat exchanger) are assumed as two black-boxes. The local heat transfer coefficient and heat transfer size is assumed ideally and pressure drops in the components are ignored.

\section{Energy balance}

CAHP cycle is based on energy balances for the internal stream and external stream. The properties of fluid at inlet and outlet are expressed in terms of temperature, pressure, concentration and enthalpy. The equations of energy balance across the components are defined as follows:

Generator 


$$
\begin{gathered}
Q_{\mathrm{gw}}+m_{5} h_{5}=m_{6} h_{6}+m_{1} h_{1} \\
Q_{g w}=m_{g w}\left(h_{9}-h_{10}\right)=m_{g w} k_{g} \cdot A_{g} \cdot \Delta T_{g} \\
m_{6}+m_{1}=m_{5}
\end{gathered}
$$

Compressor

$$
W_{c}=m_{1}\left(h_{2}-h_{1}\right) / \eta_{i s}
$$

Absorber

$$
\begin{gathered}
Q_{a}+m_{3} h_{3}=m_{8} h_{8}+m_{1} h_{2} \\
m_{3}=m_{8}+m_{1} \\
Q_{a}=m_{a w}\left(h_{12}-h_{11}\right)=m_{a w} \cdot k_{a} \cdot A_{a} \cdot \Delta T_{a}
\end{gathered}
$$

Pump

$$
W_{p}=m_{6}\left(h_{7}-h_{6}\right) / \eta_{p}
$$

Compression ratio

$$
\varepsilon=p_{2} / p_{1}
$$

At each pressure ratio, according to a screw compressor cooled with insoluble oil, the isentropic efficiency data used as follows:

$$
\eta_{i s}=-0.143+0.55 \varepsilon-0.0867 \varepsilon^{2}
$$

where $\varepsilon=2 \sim 3.5$

$$
\eta_{i s}=-0.766+0.0131 \varepsilon
$$

where $\varepsilon=3.5 \sim 10$

$$
C O P=Q_{a} /\left(W_{c}+W_{p}\right)
$$

In this study, COP corresponds to the efficiency of the machine on power consumption basis. The compression ratio of the system is calculated based on the simulation. In order to analyze the system performance, the heat source temperature and the solution concentration are chosen as input variables, and the size of heat exchanger is considered ideally.

\section{RESULTS AND DISCUSSION}

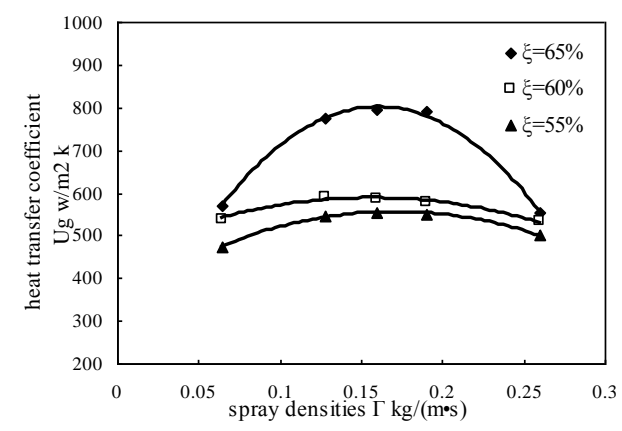

Figure 3. $U g-\Gamma$ relation with different strong solution concentration (geothermal water temperature $T_{9}=30^{\circ} \mathrm{C}$, volume flow $V g=500 \mathrm{~L} / \mathrm{h}$ )

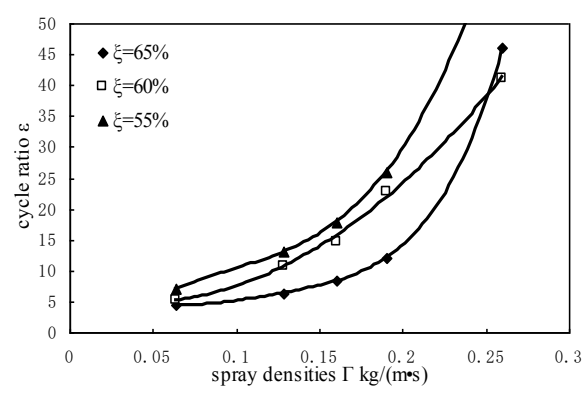

Figure 4. $\quad \varepsilon-\Gamma$ relation with different strong solution concentration (geothermal water temperature $T_{9}=30^{\circ} \mathrm{C}$, volume flow $V g=500 \mathrm{~L} / \mathrm{h}$ )

Fig .3 shows the overall heat transfer coefficient $U_{g}$ changes along with the inlet spray density $\Gamma$ varying from 0.15 to 0.35 . When the water temperature $T_{9}$ and volume flow $V_{g}$ are constant, as well as $\Gamma$ increasing, all curves show that the $U_{g}$ firstly increases and then decreases. This occurrence is resulted from the larger inlet spray and the higher velocity of film flow, and the film flow characteristic changes conducive to the heat and mass transfer. On the other hand, when the spray density exceeds the optimum value, the film becomes thickness, and the mass transfer resistance increases. Fig .4 shows the cycle ratio $\varepsilon$ increases when the spray density increases, but the tendency is gent when $\Gamma$ is less than $0.2 \mathrm{~kg} \cdot \mathrm{m}^{-1} \cdot \mathrm{s}^{-1}$. In addition, all of these curves show that the mass of ammonia vapor is also increasing with the spray density increasing. From Fig . 3 and 4, it is found the concentration has a positive effect on the heat transfer, and there is an optimum value for spry density. In this case, the optimum value is around $0.15 \mathrm{~kg} \cdot \mathrm{m}^{-1} \cdot \mathrm{s}^{-1}$.

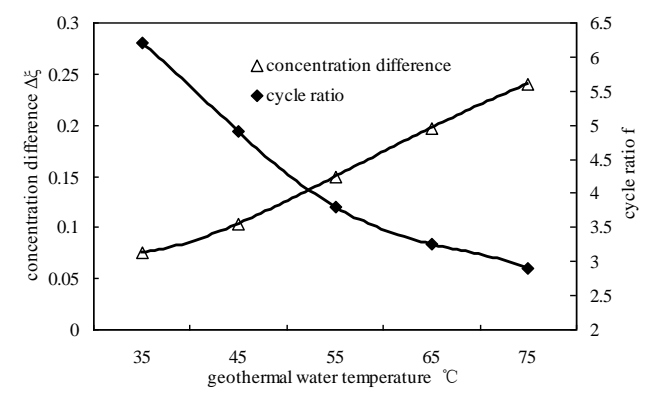

Figure 5. The effect of geothermal water temperature on concentration difference and cycle ratio. (spray density $\Gamma=0.13 \mathrm{~kg} \cdot \mathrm{m}^{-1} \cdot \mathrm{s}^{-1}$, geothermal water $V_{\mathrm{g}}=500 \mathrm{~L} / \mathrm{h}$, strong solution concentration $\xi=65 \%$ )

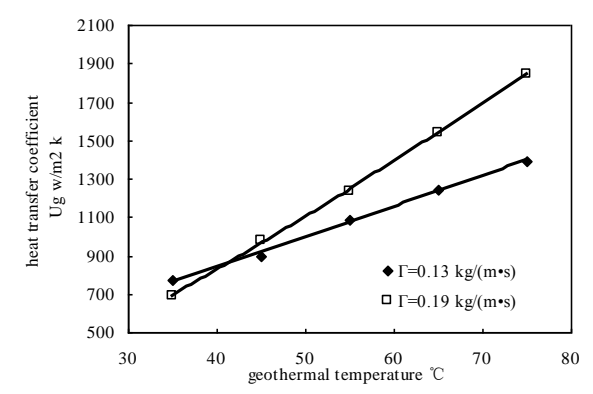

Figure 6. The changes of $U_{g}$ along with geothermal water temperature at different spray densities. (geothermal water $V_{g}=500 \mathrm{~L} / \mathrm{h}$, strong solution concentration $\xi=65 \%$ )

It is seen from Fig .6 that the heat source temperature has significant impacts on the concentration difference and cycle ratio. In CAHP system, the cycle ratio has a large effect on COP [8], which means the heat source temperature also makes a big difference on COP. The simulation shows that when the concentration is at $65 \%$, a high concentration difference about $10 \%$ can be obtained. Fig .5 shows that when the heat source temperature increases, the $U_{g}$ increases linearly. Under the same conditions, when the temperature is blow $40^{\circ} \mathrm{C}$, the value of $U_{g}$ with different spray densities is similar, which is correspond to the generator experimental research of [5]. 


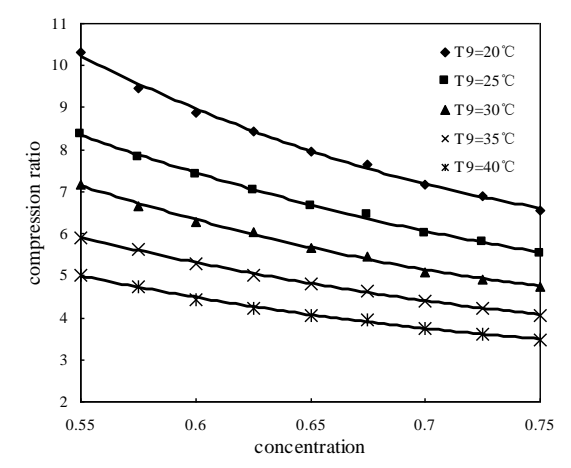

Figure 7. The changes of $\varepsilon$ along with concentration at different heat source temperatures ( heat sink temperature $T_{12}=65^{\circ} \mathrm{C}$ )

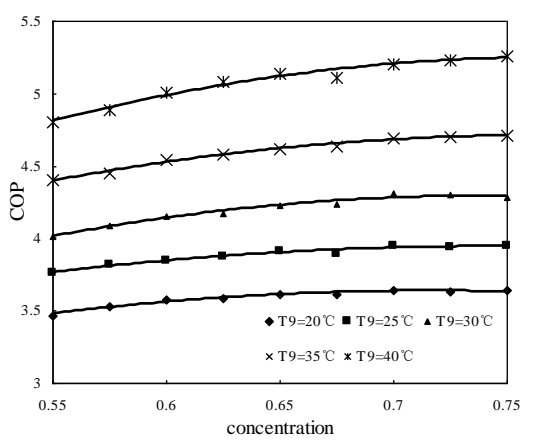

Figure 8. The changes of COP along with concentration at different heat source temperatures (heat sink temperature $T_{12}=65^{\circ} \mathrm{C}$ )

Fig .7 shows that for different geothermal water inlet temperatures $\left(T_{9}\right)$, the compression ratio $\varepsilon$ decreases as the concentration increasing. The changes of concentration have great influence on the compression ratio, and to get same heating capacity, the lower the heat source temperature, the higher compression ratio. COP changes along with the variation of $T_{9}$ shown in Fig .8. Each curve shows COP as a function of concentration for different heat source temperatures $\left(T_{9}\right)$, and at the same temperature, COP is larger for the higher heat source temperature. These curves show that when the concentration is larger than $65 \%$, COP of the system is almost constant. Results indicate that the heat of dissolution for unit mass of ammonia under different conditions is subequal, and if the compression ratio is high, the power inputted to the compressor is large, and COP decreases. It is noted that as the heat sink temperature at $65^{\circ} \mathrm{C}$, if the heat source temperature is higher than $30^{\circ} \mathrm{C}, \mathrm{COP}$ is higher than 4.0 .

\section{CONCLUSIONS}

Two models, respectively, for the generator and whole system using ammonia-water as the working fluid are proposed. The following conclusions can be drawn from the present study:
1) The maximum over all heat transfer coefficient of the out-tube falling film generator can be obtained in an optimum spray density around $0.15 \mathrm{~kg} \cdot \mathrm{m}^{-1} \cdot \mathrm{s}^{-1}$. The concentration and heat source temperature have large effects on the performance of the generator under the lowtemperature conditions, and with the concentration around $65 \%$, it can get a high concentration difference about $10 \%$.

2) In different conditions, the compression ratio always increases along with the concentration decreasing. When the concentration is higher than $70 \%, \varepsilon$ changes gently, and when it is lower than $60 \%, \varepsilon$ decreases sharply.

3) COP increases with the concentration increasing. There also exists an optimum concentration around $65 \%$.

4) The study indicates that with a high heat sink temperature between 70 and $85^{\circ} \mathrm{C}$, and low heat source temperature from 25 to $40^{\circ} \mathrm{C}$, the out-tube falling film generator is appropriate for CAHP system, and COP is above 4 .

\section{REFERENCES}

[1] Bourouis, M., Nogues, M., Boer, D. and Coronas, A. 2000. Industrial heat recovery by absorption/compression heat pump using TFE-H2O-TEGDME working mixture. Appl. Therm. Eng. 20:355-369

[2] Ventas, R., Lecuona, A., Zacarias, A., and Venegas, M. 2010. Ammonia-lithium nitrate absorption chiller with an integrated lowpressure compression booster cycle for low driving temperatures. Appl.Therm. Eng. 30:1351-1359

[3] Hulten, M., and Berntsson, T. 1999. The compression/absorption cycle-influence of same major parameters on COP and a comparison with the compression cycle. Int. J. Refrig. 22: 91-106

[4] Fukuta, M., Yanagisawa, T., Iwata, H., and Tada, K. 2002 Performance of compression/absorption hybrid refrigeration cycle with propane/mineral oil combination. Int. J. Refrig. 25:907-915

[5] Stokar, M., and Trepp, C. 1986. Compression heat pump with solution circuit part1:design and experimental results. Int. J. Refrig. 10:87-96

[6] Satapathy, P. K. 2008. Exergy analysis of a compressionabsorption system for heating and cooling applications. Int. J. Energ. Res. 32:1266-1278

[7] Stokar, M. 1987. Compression heat pump with solution circuit part2: Sensitivity analysis of construction and control parameters. Int. J. Refrig. 10:134-142

[8] Rameshkumar, A., Udayakumar, M., and Saravanan, R. 2009. Heat transfer studies on a GAXCAC(generator-absorber-exchange absorption compression) cooler. Appl. Energy 86:2056-2064

[9] Tyagi, S.T., Kim, M. S., Park, S.R., and Anand, S. 2010. Second law based performance of modified VAC hybrid heat pump system using N3H-H2O as the working fluid. Indian J. Pure. Ap. Phy. 212219

[10] Chun, K. R. and Seban, R.A. 1971. Heat transfer to evaporating liquid film, ASME J. Heat Transfer 391-396.

[11] Eckhard, A. G.. 1997. Current status of absorption/compression cycle technology. Ashare Transactions symposia 361-373 